\title{
Desenvolvimento das Habilidades Sociais na Vida de Mulheres Usuárias de Crack: Estudo de Casos Múltiplos
}

\author{
Jéssica Limberger ${ }^{1}$ \\ Ilana Andretta \\ Programa de Pós Graduação em Psicologia, Universidade do Vale do Rio dos Sinos, \\ São Leopoldo, RS, Brasil
}

\section{Resumo}

Estudos apontam a relação entre baixas habilidades sociais e o uso de drogas, mas não contemplam seus significados para mulheres usuárias de crack. Desta forma, objetiva-se compreender o desenvolvimento das habilidades sociais na trajetória de vida de tais mulheres. Trata-se de um estudo qualitativo, de casos múltiplos, com síntese de casos cruzados. Os dados foram coletados pela pesquisadora em duas etapas, sendo a primeira composta pelo questionário de dados sociodemográficos e de uso de drogas, Mini International Neuropsychiatric Interview, Inventário de Habilidades Sociais, Screening Cognitivo do Wais-III e Structured Clinical Interview for DSM Disorders. Na segunda etapa, utilizou-se a Entrevista Clínica sobre Trajetória de Vida e Habilidades Sociais. Participaram desse estudo três mulheres. Todas apresentaram dificuldades nas habilidades sociais desde a infância, com repertório adquirido através de modelos inadequados de interações sociais com seus familiares, escolares e pares. As comorbidades podem ter dificultado o uso das habilidades sociais e houve déficit nas mulheres com transtorno de personalidade borderline. Além disso, a entrevista clínica permitiu uma análise mais profunda dos dados obtidos por meio do IHS-Del Prette. Indica-se que as comorbidades sejam consideradas na avaliação das habilidades sociais e que intervenções promovam tais habilidades durante o tratamento do uso de drogas.

Palavras-chave: Habilidades sociais, mulheres, crack cocaína, transtornos relacionados ao uso substâncias, estudo de casos múltiplos

\section{Development of Social Skills in Female Crack Users: Multiple Case Study}

\footnotetext{
Abstract

Studies indicate a relationship between low levels of social skills and drug use, but do not contemplate the meanings for female crack users. Thus, the aim was to understand the development of social skills

Endereço para correspondência: Universidade do Vale do Rio dos Sinos, Escola de Saúde, Programa de Pós Graduação em Psicologia, Avenida Unisinos, 950, Bairro Cristo Rei, São Leopoldo, RS, Brasil 93020-000. E-mail: jessica.limberger.psi@gmail.com

Artigo derivado da Dissertação de Mestrado "Mulheres em tratamento pelo uso do crack: habilidades sociais e características clínicas", de autoria da primeira autora, com orientação da segunda autora, defendida em janeiro de 2016, no Programa de Pós Graduação em Psicologia da Universidade do Vale do Rio dos Sinos (UNISINOS). Bolsa de Mestrado Coordenação de Aperfeiçoamento de Pessoal de Nível Superior (CAPES) / Programa de Suporte à Pós-Graduação de Instituições de Ensino Particulares (PROSUP).

Agradecemos a CAPES pela bolsa CAPES/PROSUP de Mestrado da primeira autora.
} 
in the life trajectory of these women. This was a qualitative, multiple case study with cross-case synthesis. Data were collected by the researcher in two stages, the first consisted of the application of the socio-demographic data and drug use questionnaire, Mini International Neuropsychiatric Interview, Social Skills Inventory, Cognitive Screening of the WAIS-III and Structured Clinical Interview for DSM Disorders. In the second step, the Clinical Interview about Life Trajectory and Social Skills was used. Three women participated in this study. All presented difficulties in social skills since childhood, with repertoires acquired through inadequate models of social interactions with family, school colleagues and peers. Comorbidities may have hindered the use of social skills, which showed deficits in the women with borderline personality disorder. The clinical interview allowed a deeper analysis of the data obtained through the IHS-Del Prette. It indicated that the comorbidities were considered in the evaluation of the social skills and that interventions promoted these skills during the treatment for drug use.

Keywords: Social skills, women, crack cocaine, disorders related to substance use, multiple case study.

\section{Desarrollo de Habilidades Sociales en la Vida de Mujeres Usuarias de Crack: Estudio de Casos Múltiples}

\section{Resumen}

Estudios demuestran la relación entre bajas habilidades sociales y el uso de drogas, pero no contemplan sus significados para mujeres usuarias de crack. De esta forma, el objetivo de este trabajo es comprender el desarrollo de habilidades sociales en la trayectoria de vida de esas mujeres. Es un estudio cualitativo, de casos múltiples, con síntesis de casos cruzados. La investigadora recogió los datos en dos etapas, la primera compuesta por un cuestionario de datos sociodemográficos y de uso de drogas, Mini International Neuropsychiatric Interview, Inventario de Habilidades Sociales, Screening Cognitivo de Wais-III y Structured Clinical Interview for DSM Disorders. En la segunda etapa, se utilizó la Entrevista Clínica sobre la Trayectoria de Vida y Habilidades Sociales, participaron de este estudio tres mujeres. Todas presentaron dificultades en habilidades sociales desde la niñez, con repertorio adquirido mediante modelos inadecuados de interacciones sociales con sus familiares, escolares y pares. Es posible que las comorbidades haya dificultado el uso de habilidades sociales y también hubo déficit en las mujeres con trastorno de personalidad borderline. Además, la entrevista clínica permitió un análisis más profundo de los datos obtenidos mediante de IHS-Del Prette. Se señala que debe considerarse las comorbidades en la evaluación de habilidades sociales y que intervenciones deben platear esas habilidades durante el tratamiento de uso de drogas.

Palabras clave: Habilidades sociales, mujeres, crack cocaína, trastornos relacionados con sustancias, estudio de casos múltiples.

As habilidades sociais são diferentes classes de comportamentos que fazem parte do repertório do indíviduo, a fim de que ele possa lidar de maneira adequada com as demandas das situações interpessoais (Del Prette \& Del Prette, 2014). Tais habilidades são condições necessárias, mas não suficientes, para a competência social, que se trata de um conjunto de comportamentos bem sucedidos que contribuem no aumento dos ganhos e na diminuição das perdas para si e para as pessoas envolvidas na situação interpessal (Del Prette \& Del Prette, 2013). No decorrer do ciclo vital, as habilidades sociais se relacionam com maior qualidade de vida, na medida em que possibilitam relações interpessoais mais produtivas e satisfatórias (Feitosa, 2013; Terroso, Pedroso, \& Kurle, 2015).

As principais classes e subclasses de habilidades sociais são: habilidades sociais de comunicação (começo e manutenção de conversação e dar e receber feedback); de civilidade (expressão de cortesia de acordo com as normas e cultura do 
grupo); assertivas de enfrentamento, direito e cidadania (manifestação de opiniões e direitos em diferentes contextos); empáticas (expressão de apoio e compartilhamento solidário); de trabalho (tomada de decisões, mediação de conflitos e coordenação de grupo) e de expressão de afeto positivo (manutenção de relações de amizade, amor e solidariedade; Del Prette \& Del Prette, 2013).

As habilidades sociais são adquiridas no decorrer do desenvolvimento, a partir das situações de interação social (Terroso et al., 2015). A infância se trata de uma etapa singular na aprendizagem de tais habilidades, pois a plasticidade comportamental é característica dessa fase (Del Prette, Ferreira, Dias, \& Del Prette, 2015). Na adolescência, devido ao maior contato com os pares, há necessidade de novas habilidades nas interações, bem como de habilidades sociais referentes à capacidade de recusa nas situações de pressão dos pares para o envolvimento com comportamentos de risco, como o uso de drogas e a violência (Vorobjov, Saat, \& Kull, 2014; Wagner \& Oliveira, 2015). Na vida adulta, o nível de complexidade do uso das habilidades sociais vai aumentando, de acordo com as demandas dos diferentes contextos de interação: família, traba1ho, amigos, entre outros (Del Prette et al., 2015; Limberger \& Andretta, 2015a).

Desde a infância e nas demais etapas do desenvolvimento, existem fatores que podem dificultar o uso das habilidades sociais, como as experiências negativas nas interações sociais, a carência de modelos para a aprendizagem, além de características clínicas como a depressão e a ansiedade (Del Prette \& Del Prette, 2014; Fernandes, Falcone, \& Sardinha, 2012; Segrin, 2010; Terroso et al., 2015). As dificuldades na utilização das habilidades sociais, quando se tornam recorrentes, podem gerar déficits. Tais déficits podem ser de aquisição (não-ocorrência da habilidade social nas demandas do meio); de desempenho (ocorrência de uma habilidade específica, com frequência menor que a esperada nas demandas do ambiente); e de fluência (ocorrência da habilidade com proficiência inferior à esperada (Angélico, Crippa, \& Loureiro, 2006).
Déficits em habilidades sociais repercutem em sofrimento psicológico e problemas de comportamento, como o uso de drogas (Andretta, Limberger, \& Schneider, 2016; Feitosa, 2013; Schneider, Limberger, \& Andretta, no prelo). A literatura já tem identificado déficits específicos em usuários de drogas, quando comparados com não usuários. Conforme um estudo português com 124 usuários de drogas ilícitas, déficits nas habilidades sociais de enfrentamento e autoafirmação com risco e conversação e desenvoltura social foram identificados (Sintra, Lopes, \& Formiga, 2011). Por sua vez, déficits na autoexposição a desconhecidos e situações novas e no autocontrole da agressividade em situações aversivas foram descritos em adolescentes usuários de maconha, com diferenças significativas em relação ao grupo controle, em um estudo brasileiro com 98 participantes (Wagner \& Oliveira, 2015).

No contexto do uso do crack, um estudo brasileiro com 63 mulheres usuárias de crack evidenciou déficits na conversação e desenvoltura social, autoexposição a desconhecidos e situações novas e autocontrole da agressividade em situações aversivas (Limberger \& Andretta, no prelo). Em tal estudo, foram evidenciadas associações entre comorbidades psiquiátricas e habilidades sociais. Mulheres com Episódio Depressivo Maior apresentaram escores significativamente inferiores no autocontrole da agressividade e o déficit em habilidades sociais se associou com possuir Transtorno de Personalidade Borderline. Nessa perspectiva, na avaliação das habilidades sociais, torna-se necessário considerar as comorbidades psiquiátricas, pois estas também podem estar dificultando o desempenho de tais habilidades (Limberger, 2016).

Estudos que contemplem as habilidades sociais e o uso de drogas são predominantemente de caráter quantitativo, conforme aponta uma revisão sistemática da literatura nacional e internacional, que analisou 13 artigos sobre o tema (Schneider et al., 2016). Dos artigos analisados, todos eram quantitativos, sendo que das populações estudadas, nenhum artigo tratava especificamente das habilidades sociais de mulheres usuárias de crack. Com isso, ainda há uma lacu- 
na na literatura na compreensão das habilidades sociais em usuários de drogas a partir de uma perspectiva qualitativa.

Considerando que a qualidade das relações interpessoais (viver em um ambiente familiar instável) e os contextos de interação (associar-se a usuários e fornecedores) são fatores de risco para o uso de crack em mulheres (American Psychiatric Association [APA], 2014), há a necessidade de analisar o papel das habilidades sociais nesta população, desde a sua infância. Sendo assim, propõe-se o seguinte problema de pesquisa: "Como as habilidades sociais se desenvolvem durante a vida de mulheres usuárias de crack?". Para tanto, este estudo objetiva compreender o desenvolvimento das habilidades sociais no ciclo vital de mulheres usuárias de crack.

\section{Método}

\section{Delineamento}

Trata-se de um estudo qualitativo e transversal, sendo um estudo de casos múltiplos (Yin, 2010). Utilizou-se o COREQ - critérios consolidados para o relato de pesquisa qualitativa, a fim de garantir maior qualidade no estudo. Fo- ram seguidos os 32 itens do checklist, que são divididos em três domínios: grupo de pesquisa e reflexividade, desenho do estudo e análise dos achados (Tong, Sainsbury, \& Craig, 2007).

\section{Participantes}

Os critérios estabelecidos para participação no estudo foram: mulheres com idade entre $18 \mathrm{e}$ 59 anos, com Transtorno por Uso de Substâncias (crack) de acordo com o DSM-5 (APA, 2014), em internação hospitalar entre o sétimo e o décimo quinto dia de internação e com déficits em habilidades sociais de ao menos dois fatores, conforme pontuação no Inventário de Habilidades Sociais (IHS). Foram excluídas participantes com síndrome psicótica (verificada através do Mini International Neuropsychiatric Interview) e com prejuízos cognitivos (verificado por meio dos subtestes vocabulário e cubos do Screening Cognitivo do WAIS-III - Wechsler, 1997). Tais instrumentos serão detalhados na seção "Instrumentos".

A seleção das participantes se deu a partir de uma amostra de 13 mulheres que estavam em internação hospitalar. O fluxograma da seleção das participantes ocorreu conforme a Figura 1.

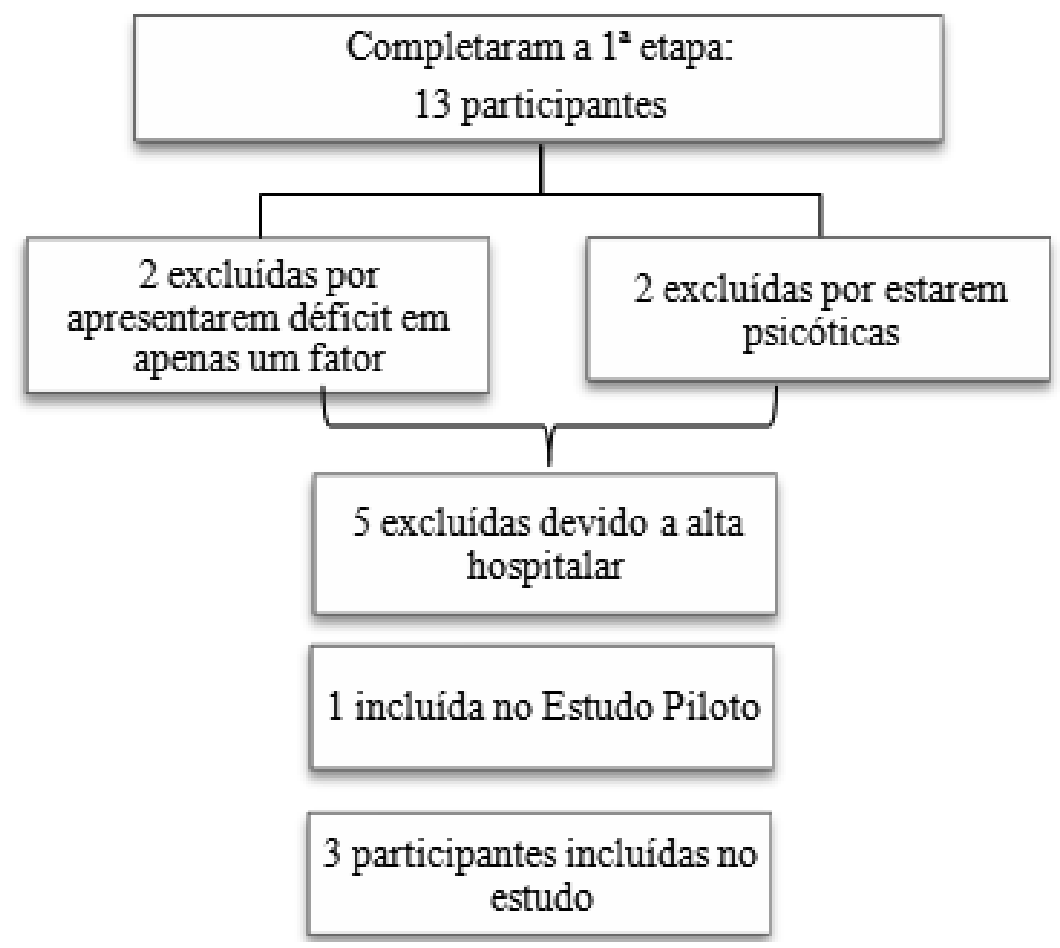

Figura 1. Fluxograma da seleção das participantes. 
Participaram deste estudo três mulheres: Isabel, Débora e Rita (nomes fictícios).

Participante 1. Isabel. Possui 36 anos, é divorciada e tem Ensino Superior Incompleto. Encontrava-se desempregada, sendo da classe econômica D. Isabel experimentou crack aos 29 anos.

Participante 2. Débora. Possui 30 anos, é solteira e tem Ensino Médio Incompleto. Também estava desempregada, sendo da classe econômica D. Débora experimentou crack aos 27 anos.

Participante 3. Rita. Possui 28 anos, é solteira e também tem Ensino Médio Incompleto. Trabalhava como manicure antes da internação, sendo da classe econômica $\mathrm{C} 1$. Rita experimentou crack aos 18 anos.

Isabel e Rita foram entrevistadas em hospitais da região noroeste do estado do Rio Grande do Sul e Débora foi entrevistada em hospital da região metropolitada de Porto Alegre (RS).

\section{Instrumentos}

Questionário de Dados Sociodemográficos e de Uso de Drogas. Foi desenvolvido pelo grupo de pesquisa "Intervenções Cognitivo Comportamentais: Ensino e Pesquisa". É composto por questões abertas e fechadas acerca dos dados sociodemográficos e dos familiares (idade, escolaridade, com quem mora, quais familiares possuem ou possuíam problemas com o uso de alguma droga, etc), Critérios de Classificação Econômica Brasil da Associação Brasileira de Empresas de Pesquisa (ABEP, 2015), dados sobre o uso de drogas (quando experimentou pela primeira vez, frequência e intensidade do uso no último ano) e critérios do DSM-5 (APA, 2014) para diagnóstico de Transtorno por Uso de Substâncias.

Mini International Neuropsychiatric Interview (MINI). Trata-se de uma entrevista clínica compatível com os critérios diagnósticos do DSM-IV-TR (APA, 2002) que avalia presença de síndrome psicótica e comorbidades psiquiátricas, além do risco de suicídio. Foi desenvolvida por Sheehan et al. (1998) e validada para o Brasil por Amorim (2000). Na validação, os índices Kappa demonstraram confiabilidade nas categorias diagnósticas $(0,86$ a 1$)$ e nos transtornos psicóticos (0,62 a 0,95; Amorim, 2000).

Screening Cognitivo do WAIS-III. Teste de uso exclusivo dos psicólogos, foi desenvolvido por Wechsler (1997) e adaptado e padronizado para o Brasil por Nascimento (2004). O screening compreende os subtestes vocabulário e cubos com valores de alpha satisfatórios ( $\alpha$ $=0,92$ e $\alpha=0,83)$ respectivamente. O subteste vocabulário avalia a compreensão verbal, a partir de palavras apresentadas ao examinando, que deve defini-las oralmente. O subteste cubos avalia a organização perceptual através de um conjunto de padrões geométricos bidimensionais que o examinando deve reproduzir usando cubos de duas cores (Nascimento, 2004).

Inventário de Habilidades Sociais (IHS). Desenvolvido por Del Prette e Del Prette (2001), também de uso exclusivo do psicólogo, caracteriza as habilidades sociais em diferentes situações: trabalho, escola, família e cotidiano (Del Prette \& Del Prette, 2001). O Inventário é de autorrelato, composto por 38 itens, em escala do tipo Likert, com cinco pontos que variam de nunca à raramente e sempre ou quase sempre. O IHS possui Alfa de Cronbach de 0,75 e estabilidade teste-reteste $(\mathrm{r}=0,90 ; p=0,001)$. A análise fatorial revelou uma estrutura de cinco fatores que reúnem habilidades sociais de: (a) enfrentamento e autoafirmação com risco - indica a capacidade de lidar com situações que necessitam afirmação e defesa de direitos, além de autoestima; (b) autoafirmação na expressão de afeto positivo - compõe habilidades como elogiar e agradecer elogios e defender em grupo outra pessoa; (c) conversação e desenvoltura social - contempla o traquejo social, com a utilização de normas do relacionamento cotidiano; (d) autoexposição a desconhecidos e situações novas - inclui situações de maior risco de reação indesejável do outro, como a abordagem a pessoas desconhecidas; (e) autocontrole da agressividade a situações aversivas - refere-se à expressão de desagrado ou raiva de maneira socialmente competente (Del Prette \& Del Prette, 2001).

Structured Clinical Interview for DSM Disorders (SCID-II). Desenvolvida por First, Gibbon, Spitzer e Williams (1997) e traduzida 
para o português (Brasil) por Melo e Rangé (2008), trata-se de uma entrevista semi-estruturada, que busca identificar Transtornos de Personalidade de acordo com o DSM-IV-TR (APA, 2002). Nesta pesquisa, foram investigados os Transtornos de Personalidade Histriônico, Narcisista, Borderline e Antissocial.

Entrevista Clínica sobre Trajetória de Vida e Habilidades Sociais. Foi desenvolvida pela pesquisadora e sua orientadora, a partir de uma revisão de literatura sobre o uso de drogas e as habilidades sociais (Schneider et al., 2016). Além disso, embasou-se no campo teórico-prático das habilidades sociais, a partir dos constructos de Del Prette e Del Prette $(2001,2014)$. A entrevista é composta por um rapport, seguido de perguntas abertas sobre a história de vida e as habilidades sociais de conversação e desenvoltura social; expressão de afeto positivo; defesa de direitos; interação com desconhecidos e situações novas e reação a situações aversivas. Posterior à elaboração inicial da entrevista, a mesma foi avaliada por uma terceira psicóloga, com experiência na área das habilidades sociais, que sugeriu alterações. Além disso, realizou-se um estudo piloto com uma mulher usuária de crack, cuja entrevista foi conduzida pela pesquisadora em um hospital da região metropolitana. A partir do estudo piloto, foram realizadas alterações, como as perguntas serem mais abrangentes e a linguagem adaptada, a fim de tornar a entrevista mais clara e compreensível.

\section{Procedimentos Éticos}

Este estudo foi aprovado pelo Comitê de Ética em Pesquisa, sob parecer número 012/2015, estando de acordo com as diretrizes internacionais do Committee on Publication Ethics (COPE). Após a Carta de Anuência dos hospitais, o procedimento de consentimento livre e esclarecido se deu a partir do contato presencial com as participantes, no hospital onde estavam internadas. Realizou-se o convite para participar da pesquisa, sendo explicados os objetivos da pesquisa e a voluntariedade no estudo, assegurando o sigilo dos dados e o anonimato. $\mathrm{O}$ Termo de Consentimento Livre e Esclarecido -
TCLE foi lido e explicado de maneira individual para cada participante que, ao concordar, assinou o termo em duas vias, sendo que uma via ficou com a participante e a outra com a pesquisadora. A devolução dos resultados da pesquisa foi oferecida às participantes e aos respectivos hospitais. O estudo contou com duas etapas de coleta de dados, desta forma, para cada etapa houve um TCLE.

\section{Procedimentos de Coleta de Dados}

Os dados foram coletados em três hospitais com leito de internação para desintoxicação devido ao uso do crack, provenientes da região noroeste e metropolitana do Rio Grande do Sul. Tais hospitais eram vinculados ao Sistema Único de Saúde (SUS). As entrevistas foram realizadas individualmente, em salas onde ficavam apenas a pesquisadora e a participante.

$\mathrm{Na}$ primeria etapa, aplicou-se os instrumentos na seguinte ordem: Questionário de Dados Sociodemográficos e de Uso de Drogas, Mini International Neuropsychiatric Interview (MINI), Screening Cognitivo do WAIS-III, Inventário de Habilidades Sociais (IHS) e Structured Clinical Interview for DSM Disorders (SCID-II). $\mathrm{Na}$ segunda etapa, aplicou-se a Entrevista Clínica sobre habilidades sociais e trajetória de vida, sendo gravada em áudio. A entrevista foi conduzida pela pesquisadora, que é psicóloga e no período do estudo atuava como bolsista em regime de dedicação exclusiva ao Mestrado. A pesquisadora possui experiência no atendimento familiar de usuários de drogas, durante o período de quatro anos em que se encontrava na graduação, seguida da intensificação dos estudos sobre o uso de drogas no momento da pesquisa, além de supervisão com sua orientadora acerca da condução das entrevistas. O relacionamento da pesquisadora com os participantes foi estabelecido no início do estudo. Com isso, as participantes tinham conhecimento da formação da pesquisadora, da instituição a qual estava vinculada e também dos objetivos da pesquisa. Entretanto, hipóteses acerca do estudo não foram mencionadas às participantes. Nas duas etapas, não foram realizadas anotações de campo. 


\section{Procedimentos de Análise de Dados}

Os dados da primeira etapa foram tabulados no programa Statistical Package for Social Sciences - SPSS, versão 20.0, por apenas uma pessoa, integrante do grupo de pesquisa. O questionário foi utilizado para a caracterização de cada caso. A MINI foi corrigida de acordo com os critérios indicados na entrevista para contemplar a presença dos diagnósticos identificados. Considerando o prejuízo cognitivo um critério de exclusão, a correção do Screening Cognitivo do WAIS-III foi realizada por dois juízes independentes, e em necessidade de consenso, um terceiro juiz foi acionado. A partir da subtração do escore ponderado de vocabulário para o escore ponderado de cubos, a diferença de três pontos ou mais indicou prejuízo cognitivo, conforme Cunha (1993) e Feldens, Silva e Oliveira (2011). A correção do Inventário de Habilidades Sociais se deu de forma simplificada, com base na inversão de itens específicos e seguida da média simples dos valores obtidos, conforme Del Prette e Del Prette (2001) orientam. A interpretação dos escores se baseou na posição, em percentis, em relação ao seu subgrupo de referência do mesmo sexo e idade. Valores situados no percentil 50 indicaram posição mediana, valores acima de 75\% indicaram altos fatores em habilidades sociais e valores abaixo de $25 \%$ indicam déficits no repertório de habilidades sociais (Del Prette \& Del Prette, 2001). Por fim, a correção da Structured Clinical Interview for DSM Disorders (SCID-II) se deu a partir da presença ou ausência dos critérios diagnósticos de cada transtorno explorado na entrevista.

Os dados provenientes da segunda etapa Entrevista Clínica sobre Trajetória de Vida e Habilidades Sociais - foram transcritos na íntegra. Posteriormente, cada entrevista foi lida e relida pela pesquisadora, a fim de identificar características recorrentes e informações que contemplassem os objetivos do estudo. Com tais dados, foram criados quatro eixos norteadores para análise, definidos a posteriori: (a) corresponde à infância; (b) trata da adolescência; (c) contempla o início do uso de drogas; e (d) versa sobre o momento de vida atual. A análise das habilidades sociais foi realizada de forma transversal em cada eixo. Por fim, buscando garantir maior qualidade na análise, foram investigadas as semelhanças e as singularidades dos casos a partir da síntese de casos cruzados, de acordo com Yin (2010).

\section{Resultados e Discussão}

A partir da correção dos instrumentos da primeira etapa, foram identificados os seguintes dados, conforme a Tabela 1 a seguir.

\section{Caso 1 - Isabel}

Isabel possui 36 anos. Atualmente, encontra-se desempregada, seu último emprego foi como Técnica em Enfermagem, há dois anos. Possui quatro filhas, de 21, 13, 12 e 10 anos, sendo que as três moram com o pai (ex-marido de Isabel) e a filha mais velha mora com o namorado e a filha do casal. A internação atual é voluntária e sua motivação para o tratamento foi devido aos grandes prejuízos do uso do crack, relatando uma vontade de voltar à sua vida normal.

Infância. Isabel relata que teve uma infância boa: "era uma criança que tinha tudo, a minha mãe me dava tudo". Todavia, refere constantes brigas com sua mãe e a falta do pai, que era comerciante e viajava muito. Sobre os desentendimentos com a mãe, aponta: "Eu acho que eu nunca consegui mostrar para minha mãe o que eu estava sentindo realmente ou como eu me sentia". Na entrada para a escola e nos demais anos escolares, Isabel possuía apenas uma amiga, sendo que se ela faltasse "se sentia perdida". Ela aponta que seu jeito de ser na infância era "quieta e caladinha". Para Isabel, os cursos que realizou na infância contribuíram para que sua timidez fosse menos intensa. Ela comenta a participação desde cedo no coral da igreja e em cursos de pintura. Além disso, também aponta que apesar da timidez sempre foi "educada $e$ cordial".

Adolescência. Conforme foi crescendo, algumas dificuldades de interação foram se intensificando, principalmente no que diz respeito ao grupo de amigos. Segundo ela, sua mãe não a deixava sair de casa e as amigas não gostavam de ir à sua casa devido à agressividade de sua 
Tabela 1

Classificação das Habilidades Sociais e Características Clínicas

\begin{tabular}{|c|c|c|c|}
\hline Características & Isabel & Débora & Rita \\
\hline $\begin{array}{l}\text { Transtorno por Uso de } \\
\text { Substâncias - } \text { crack }^{1}\end{array}$ & Grave & Grave & Grave \\
\hline $\begin{array}{l}\text { Transtorno por Uso de Outras } \\
\text { Substâncias }^{1}\end{array}$ & Tabaco & Não possui & Tabaco \\
\hline $\begin{array}{l}\text { Escore Total de Habilidades } \\
\text { Sociais }^{2}\end{array}$ & Déficit & $\begin{array}{l}\text { Repertório abaixo } \\
\text { da media }\end{array}$ & $\begin{array}{l}\text { Repertório bastante } \\
\text { elaborado }\end{array}$ \\
\hline $\begin{array}{l}\text { Enfrentamento e autoafirmação } \\
\text { com risco }^{2}\end{array}$ & $\begin{array}{l}\text { Repertório acima } \\
\text { da média }\end{array}$ & Repertório médio & $\begin{array}{c}\text { Repertório bastante } \\
\text { elaborado }\end{array}$ \\
\hline $\begin{array}{l}\text { Autoafirmação na expressão de } \\
\text { afeto positivo }\end{array}$ & Déficit & Déficit & Déficit \\
\hline $\begin{array}{l}\text { Conversação e desenvoltura } \\
\text { social }^{2}\end{array}$ & Déficit & Déficit & $\begin{array}{c}\text { Repertório bastante } \\
\text { elaborado }\end{array}$ \\
\hline $\begin{array}{l}\text { Autoexposição a desconhecidos } \\
\text { e situações novas }{ }^{2}\end{array}$ & Déficit & Déficit & $\begin{array}{l}\text { Repertório bastante } \\
\text { elaborado }\end{array}$ \\
\hline Autocontrole da Agressividade ${ }^{2}$ & Déficit & $\begin{array}{c}\text { Repertório bastante } \\
\text { elaborado }\end{array}$ & Déficit \\
\hline Comorbidades psiquiátricas $^{3}$ & $\begin{array}{l}\text { Episódio Depressivo } \\
\text { Maior Atual, Risco de } \\
\text { Suicídio, Transtorno de } \\
\text { Ansiedade generalizada }\end{array}$ & $\begin{array}{l}\text { Episódio Depressivo } \\
\text { Maior Atual }\end{array}$ & $\begin{array}{l}\text { Episódio Depressivo } \\
\text { Maior Atual, Risco de } \\
\text { Suicídio, Transtorno de } \\
\text { Ansiedade generalizada }\end{array}$ \\
\hline Transtorno de Personalidade ${ }^{3}$ & $\begin{array}{c}\text { Transtorno de } \\
\text { Personalidade Borderline }\end{array}$ & Não possui & $\begin{array}{c}\text { Transtorno de } \\
\text { Personalidade Borderline }\end{array}$ \\
\hline
\end{tabular}

Nota. ${ }^{1}$ De acordo com os critérios diagnósticos do DMS-5. ${ }^{2}$ De acordo com o Inventário de Habilidades Sociais. ${ }^{3}$ De acordo com as entrevistas diagnósticas com base no DSM-IV.

mãe. Ela recorda: "Minhas amigas diziam: Ah... na casa da Isabel não dá para a gente ir". Com medo da mãe, relata que começou a namorar escondido. Ainda aos 14 anos engravidou, e seus pais a obrigaram a se casar. Desde então, saiu de casa e não contou mais com a ajuda dos pais, sendo tirada dos cursos que frequentava. Ela aponta que não conseguiu pedir para que eles a mantivessem nos cursos e que a auxiliassem financeiramente, pois sentia muita vergonha. Além disso, refere outras dificuldades de interação, como fazer perguntas a desconhecidos.

Uso de Drogas. Constantemente Isabel via a sua mãe consumindo álcool, principalmente quando o pai de Isabel estava viajando. Entretanto, sua mãe nunca assumiu os problemas com o uso de álcool e não buscou tratamento. A primeira droga experimentada por Isabel foi a maconha, em um grupo de amigos, por medo de que não fosse aceita no grupo. Ao experimentar não gostou, pois a droga lhe fez mal e provocou náuseas. Também experimentou cocaína e devido a "um problema no nariz" nunca mais usou. Nessas circunstâncias, diz que conseguia dizer não a tais drogas, pois ambas lhe fizeram mal.

Isabel experimentou crack aos 28 anos, quando se separou do marido e começou a namorar um usuário de álcool e cocaína. Ela relata que estavam em um grupo de pessoas usando cocaína e maconha e se sentiu "excluída" por não poder usar tais drogas, pois "faziam mal". Neste dia, chegou um vizinho oferecendo crack e ela aceitou. Isabel relata que no início começou a usar enquanto o namorado usava cocaína, mas depois seu namorado também começou a utilizar o crack, sendo que ambos desenvolveram um pa- 
drão de uso intenso. Com isso, Isabel não conseguiu concluir a graduação no ano final do curso e foi demitida do trabalho.

No contexto do uso de drogas, Isabel aponta a dificuldade de recusar o crack do namorado:

Quando meu namorado chegava com a pedra parece que eu tinha que compartilhar aquele momento com ele. Eu tinha que ter aquele momento com ele. . . Eu até tentei recusar e disse para ele um dia: "ó, fuma no outro quarto, porque eu não quero mais ver você fumando". Mas dai ele veio lá na porta pedir uma coisa e eu falei: "ai, então entra aqui".

Tal dificuldade também era em relação aos outros usuários, sendo motivo de gozação.

Quando eu recusei um pega (sic) de alguém, sempre debocharam de mim. Eles diziam: "nossa, ela tá recusando um pedaço de pedra!" E muitas vezes eles me enchiam de droga, que eu nem conseguia mais fumar. Eu acabava dando para os outros.

Idade Adulta. Isabel percebe uma evolução na interação com as pessoas na idade adulta. Relata, inclusive, uma situação na qual o professor lhe pediu que apresentasse um trabalho sem ler. Após conseguir realizar a apresentação, o professor a elogiou. Segundo ela:

Eu acho que, com o passar do tempo, eu fui sendo diferente, porque quando eu era mais nova era muito mais calada. Depois com o curso técnico e depois com a faculdade, quando tive que começar a apresentar trabalhos nas aulas, eu comecei a falar mais.

Algumas semelhanças com sua filha mais velha são percebidas por Isabel:

Ela é igualzinha ... Se a gente vai em uma loja comprar roupa, ela fica com vergonha de pedir as coisas para ela. Dai ela me cutuca. Ai eu tenho que pedir por ela, sabe? Mesmo agora, ainda ela sendo de maior. É engraçado que ela ainda tem vergonha. Eu tenho que ajudar, interferir por ela, mesmo sabendo que eu também passei por isso várias vezes.

No contexto do trabalho, Isabel diz que possuía dificuldades na comunicação entre ela e seu chefe. Em situações que necessita expressar de- sagrado, Isabel diz que não consegue falar o que está pensando, por medo da reação que a pessoa terá. "Acho que eu nunca fui muito de mostrar esse meu lado de direitos". No momento da internação hospitalar, esta dificuldade também se mostra presente:

É frustrante, porque, às vezes, tem coisas que me incomodam, que nem aqui no hospital, quando eu quero ficar quieta no meu canto e alguém tá falando . . mas mesmo assim, eu continuo respondendo, educadamente, e com sorriso falso no rosto para dizer que eu estou escutando ela e está tudo bem.

No momento da internação hospitalar, Isabel caracteriza suas interações com cordialidade e educação. Refere que em situações nas quais a cordialidade não é retribuída, sente-se "como se estivesse levando um tapão na cara".

\section{Caso 2 - Débora}

Débora possui 30 anos, estava desempregada no momento anterior da internação hospitalar. Sua última profissão foi de auxiliar de cozinha, há três meses. Mora com seus quatro filhos, que possuem 12, 9, 6 e 3 anos. A internação foi voluntária, pois quer ser um exemplo para os seus filhos. Conta com uma irmã no cuidado dos seus filhos durante a internação.

Infância. Débora relata que teve uma infância boa.

Minha mãe era uma pessoa boa, a gente foi criado só por ela. Ela levava nós no parquinho, ela sempre levava nós para a escola. Eu tenho duas irmãs também que são maravilhosas. Minha infância foi ótima, foi com o decorrer do tempo mesmo que deu os erros.

Aos cinco anos, os pais de Débora se separaram e a partir de então teve pouco contato com o pai. Quando era pequena e precisava pedir algo, Débora refere: "Eu corria sempre para a mãe, pra ela pedir por mim", sendo tímida e "resguardada".

Adolescência. Débora recorda da adolescência como "uma época boa", embora também relate que não saía para festas: " $A$ mãe não dei- 
xava. Ela não gostava que a gente saísse à noite, ela tinha medo". Nas situações de interação social, Débora recorda que sempre preferiu que as pessoas iniciassem as conversas e lhe fizessem as perguntas, para então ela começar a conversar, pois achava que "ia falar besteira".

Uso de Drogas. Quando Débora tinha 12 anos, começou a fumar cigarro. Ao ver sua mãe fumando, passou a fumar escondida. $\mathrm{O}$ uso do crack ocorreu aos 25 anos, dois anos após o falecimento da sua mãe. Na ocasião, seu marido estava preso devido à venda de drogas, e experimentou crack através da cunhada que ofereceu. Ela diz que esse foi o único relacionamento com uma pessoa "criminosa" e que ele nunca havia oferecido crack para ela. O uso do crack seguiu por oito meses e, posteriormente, ficou aproximadamente três anos sem usar, período em que estava com um companheiro que não era usuário. Após a separação deste companheiro, voltou a usar crack. Segundo ela: "Botei ele pra rua dizendo que ele que me incomodava... Mas eu acho que na minha cabeça, agora pensando, que isso foi só uma desculpa, porque eu já estava com vontade de usar". Devido ao uso do crack, Débora aponta que perdeu amizades: "Antigamente elas me davam bastante atenção. Hoje em dia eu converso com elas e elas trocam meia dúzia de palavras e ai dizem: 'tchau, eu tenho que ir lá, deixa que outra hora a gente conversa mais".

Idade Adulta. Débora diz que ainda é tímida, comportamento semelhante ao do seu filho:

O meu guri mais velho é bem tímido. Os outros não, conversam, brincam com ele, que ele tá sempre quietinho no canto dele. Se puxar conversa com ele, ele conversa. Se não, ele fica ali bem quietinho. Ele é bem parecido comigo.

Ela diz que continua preferindo que as outras pessoas puxem um assunto com ela, pois tem "medo de falar besteira, de começar a falar coisas que não é. Então eu prefiro que as outras pessoas entrem em um assunto pra mim poder falar". Acerca dos contextos de interação, Débora refere que encontra dificuldades:

Porque, geralmente, ninguém quer ter perto uma pessoa que usa drogas. Ninguém vai sentar e conversar com um usuário. É difícil se relacionar com outras pessoas que não usam ... E eu acabo nem puxando assunto, porque geralmente a gente nem quer conversar mais. Já sabe como vai ser tratado. Dai nem busca mais.

Nas situações em que deixa de falar com as pessoas por receio, Débora relata:

Eu sinto que fico meio vazia né? Porque dai eu não converso, só escuto. É que nem o grupo com a psicóloga, que é raro eu abrir a boca para falar, eu só escuto. Eu fico pensando: nossa, se eu falar eu vou falar besteira. Ai eu penso muito, que eu não vou falar porque quando vê, falo algo que não tem nada a ver. Dai eu fico só ouvindo eles falando.

Em situações de defesa de direitos, diz que fica nervosa: "Mas dai eu brigo mesmo (risos). Pelos meus direitos eu brigo".

\section{Caso 3 - Rita}

Rita possui 28 anos, antes de sua internação trabalhava como manicure. Mora com os filhos de dois e oito anos e com seu companheiro. A internação é voluntária, sendo que a motivação para buscar tratamento foi reconhecer que estava usando demais, que estava "acabada".

Infância. Ao falar sobre sua história, Rita diz que sua vida "nunca foi muito boa, não gosto, não me faz bem relembrar". No decorrer da entrevista, refere:

Eu nasci lutando porque a minha mãe tentou me abortar duas vezes e não conseguiu. Com um ano e três meses, ela me jogou na lata de lixo. E eu estou aqui ... Por isso que eu digo, eu luto, eu virei uma leoa porque eu aprendi.

Aos dez anos, seu pai faleceu, sendo criada pelos avós. $\mathrm{Na}$ escola, aponta que as amizades com os colegas eram mais distantes e que muitas vezes se desentendiam, gerando brigas. No convívio familiar, relata constantes discussões e gritos entre ela e seus irmãos.

Adolescência. Durante a adolescência, Rita diz que sempre foi "mal educada" ao interagir com as pessoas, e as brigas com os irmãos seguiram, considerando apenas o apoio de sua irmã 
mais velha. Na adolescência, apesar de referir muitos amigos, comenta que não contava com ninguém nas horas de dificuldade: "Eu ficava na minha, eu não sou muito de contar problema, eu sou de guardar pra mim".

Uso de Drogas. Rita recorda que seu irmão fumava maconha na sua frente: "ele soprava a maconha no meu rosto, até que um dia eu experimentei". Com isso, experimentou a maconha aos 16, usando esporadicamente até os 20 anos. Aos 17, experimentou cigarro e continuou usando até os 20 anos. Rita trabalhou como prostituta dos 20 aos 21 anos e começou a usar cocaína "para ficar acordada e aguentar". Logo que deixou de prostituir-se, experimentou o crack "de bobeira", a partir de uma amiga:

Uma amiga minha fumava e ia para minha casa. Eu disse pra ela, o que tu quer com isso? Um dia ela chegou muito chapada e pediu para eu buscar pra ela, eu disse vou pegar e acho que vou pegar pra mim também. Aí fumei mas não me deu nada, pensei, vou fumar mais uma. E fumei mais uma, mais uma e mais uma.

Desde então, Rita teve intervalos de até dois anos que deixou de usar, mas que acabou voltando a usar durante os oito anos de uso do crack.

Idade Adulta. No dia a dia, Rita refere que cumprimenta as pessoas. Para ela, "o cumprimento é até uma forma de educação, é uma forma até de às vezes a gente fazer uma aproximação com a pessoa né, um vínculo". Ela também diz que elogia as pessoas por "darem as coisas sem esperar receber", elogiando principalmente seus filhos: "Minha filha, meu filho são quem eu mais elogio ... como se as crianças mais bonitas do mundo fossem eles, os melhores do mundo, eu digo que eles são os melhores filhos do mundo". Em situações nas quais necessita pedir ajuda, ela recorre à irmã que mais confia e também pede ajuda ao marido, e quando não pede ajuda para a irmã ou para o marido, prefere pedir ajuda para desconhecidos: "Porque os conhecidos assim ó, muitos conhecidos você ajuda, só que na hora que você precisa de ajuda, eles te viram as costas, eles não sabem lembrar que antigamente, você ajudou eles".
Quando Rita se sente incomodada com algo, diz que é "super mal educada". Segundo ela: "Leão passa vergonha perto de mim, eu tento tudo numa boa, mas se não dá numa boa, eu perco, eu perco o tino e ninguém me segura". Nos momentos em que precisa lidar com a raiva, diz: Eu saio de perto das pessoas. Já saio, já levanto, já bato uma porta, já falo bem alto, já digo "ó, vamos desligar", se tiver som ligado, desligo e digo "ó, não quero que ligue mais e acabou a história, acabou a festinha, e me deixem bem quieta" e viro as costas e saio.

As situações de dificuldade em lidar com a raiva também se expressaram no tratamento: "Eu já discuti com a enfermeira, já me deu vontade de sair daqui de uma vez".

\section{Síntese dos Casos Cruzados}

As características gerais das participantes apontam para semelhanças no uso do crack de maneira grave. Além disso, nos três casos há déficits na autoafirmação e expressão de afeto positivo e repertório médio ou acima da média no enfrentamento e autoafirmação com risco.

O Transtorno de Personalidade Borderline foi identificado em Isabel e Rita, que também se assemelham no uso de tabaco concomitante ao uso do crack e na presença das mesmas comorbidades (Episódio Depressivo Maior Atual e Transtorno de Ansiedade Generalizada), bem como o risco de suicídio. Com isso, compreende-se que a presença do Transtorno de Personalidade pode repercutir em maiores déficits de HS, conforme o caso de Isabel e em maior agressividade no estilo de resposta, como é o caso de Rita. Sabe-se que o Transtorno de Personalidade Borderline se caracteriza pela impulsividade e padrões de instabilidade nas relações interpessoais (APA, 2014). Entretanto, não é apenas a presença do transtorno de personalidade que define possíveis relações com um déficit no repertório de habilidades sociais. Dessa forma, se novas interações sociais fossem desenvolvidas em contextos promotores de habilidades sociais (como em Treinamentos de Habilidades Sociais), a impulsividade possivelmente não ocorreria de maneira 
tão intensa ou as participantes desenvolveriam a classe dentro das HS conhecida como autocontrole da agressividade (Del Prette \& Del Prette, 2013). A partir do caso de Débora, que não apresentou nenhum dos transtornos de personalidade avaliados e possui menores comorbidades psiquiátricas em relação às outras participantes, percebe-se que o principal aspecto é sua timidez e seu medo de "falar besteira". Esse receio do julgamento alheio pode estar associado com o Episódio Depressivo Maior Atual que apresenta. Assim, tal comorbidade dificulta o uso das habilidades sociais e necessita ser avaliada com atenção (Segrin, 2010). Nesse contexto, o Treinamento em Habilidades Sociais pode contribuir para melhoras na depressão, iniciando com as habilidades sociais de maior facilidade, a fim de estimular os pontos fortes dos participantes (Del Prette \& Del Prette, 2014). Conforme um estudo de caso único de um paciente com depressão e ideação suicida, houve melhoras após a realização do Treinamento em Habilidades Sociais (16 sessões, em um período de três meses), que se mantiveram após um follow-up de três meses (Jansson, 1984).

Para além das características gerais, identifica-se que no eixo infância os casos compartilham dificuldades específicas no uso das habilidades sociais: Isabel e Débora relatam timidez ao expressar seus sentimentos e Rita possui respostas agressivas frente às situações. Desta forma, percebe-se que o contexto familiar possui um importante papel na aprendizagem das habilidades sociais, pois comumente são aprendidas, principalmente, a partir dos relacionamentos interpessoais com os pais na infância (Limberger \& Andretta, 2015a). Conforme o caso de Rita, ela refere: "virei uma leoa porque aprendi", em que também relata que viveu em um ambiente com constantes brigas e discussões. Nesse sentido, as dificuldades dos pais em expressar adequadamente tanto a raiva como o desagrado constitui um modelo de aprendizagem inadequado no que diz respeito às habilidades sociais para os filhos (Del Prette \& Del Prette, 2014).

Os três casos compartilham de dificuldades nas habilidades sociais durante a adolescência, cada qual com sua especificidade. Para Isabel e
Rita, padrões semelhantes da infância se mantém. Na infância, Isabel relatava dificuldades na comunicação com sua mãe e na adolescência aponta a dificuldade em fazer pedidos e expressar suas necessidades. Por sua vez, o comportamento tímido de Débora, que estava presente na infância, também se mantém na adolescência, na dificuldade de iniciar conversas. Assim, as classes de habilidades sociais de comunicação e assertividade se mostraram com dificuldades desde a infância, podendo relacionar-se inclusive no desempenho acadêmico, sendo que Débora e Rita deixaram de estudar. Nesse sentido, um estudo longitudinal evidenciou um efeito bidirecional entre o desempenho acadêmico e as habilidades sociais (Caemmerer \& Keith, 2015).

A manutenção das dificuldades interpessoais apontadas nos três casos pode ser compreendida pela falta de novas experiências de aprendizagem, seja a partir dos pares, dos familiares ou ainda de intervenções específicas, como o Treinamento em Habilidades Sociais. No caso de Rita, ao guardar seus sentimentos para si, sem perceber uma rede de apoio na adolescência, há impedimentos do exercício das demais classes de habilidades sociais, visto que o apoio social de colegas, pais e professores contribui principalmente nas habilidades sociais de adolescentes do sexo feminino, quando comparadas com adolescentes do sexo masculino (Nilsen, Karevold, Røysamb, Gustavson, \& Mathiesen, 2013). Nos três casos, intervenções voltadas ao desenvolvimento de habilidades sociais poderiam ser realizadas na adolescência em contexto escolar, dada a importância do papel social que a escola ocupa na vida dos adolescentes (Andretta, Limberger, \& Oliveira, 2014).

Tanto Isabel como Débora tiveram pouco contato com os pares na adolescência. Nessa etapa, a falta de contato com os pares e as relações sociais que propiciam pouco contato social, implicam em maior probabilidade de dificuldades comportamentais e emocionais, como o uso de drogas (Leme, Fernandes, Jovarini, \& Achkar, 2015) Nessa perspectiva, adolescentes que não desenvolveram a habilidade de interagir socialmente de maneira satisfatória, podem ser rejeitados por seus pares e utilizar as substâncias 
psicoativas como uma maneira desadaptativa de lidar com suas dificuldades (Wagner \& Oliveira, 2015). Conforme um estudo realizado na Estônia com 2.460 estudantes entre 15 e 16 anos, identificou-se que os adolescentes que possuíam baixas habilidades sociais tiveram maiores chances do uso do tabaco, maconha, sedativos e inalantes (Vorobjov et al., 2014). Nos casos de Débora e Rita, o uso de tabaco e maconha foram relatados ainda na adolescência, como será apresentado no eixo a seguir.

No eixo uso de drogas, observa-se que entre a infância e a adolescência, nos três casos as mulheres viam seus familiares utilizando drogas de maneira problemática e muitas vezes como forma de fuga de seus problemas do dia a dia, sendo expostas assim, a um modelo inadequado de resolução de problemas (Del Prette \& Del Prette, 2014). Nesse sentido, percebe-se que os jovens tendem a reproduzir os comportamentos inadequados que aprendem durante sua infância e adolescência, sendo que seus familiares aparecem como os principais modelos, que se configuram como respostas não adaptativas às interveniências do dia a dia (Botvin \& Griffin, 2015). Destaca-se que especialmente no uso do crack, nos três casos foram pessoas próximas que ofereceram tal droga. Além disso, Isabel relata que ao ver o namorado usando crack, queria " $\mathrm{com}$ partilhar" aquele momento com ele. Assim, percebe-se além da dependência, a droga acaba tendo um papel de articulador nos relacionamentos, dificultando ainda mais a saída deste círculo vicioso, conforme o caso de Isabel.

No eixo vida adulta, são encontradas semelhanças entre Isabel e Débora com seus filhos mais velhos. No caso da filha de Isabel, a dificuldade em pedir informações, e no caso de Débora, a timidez de seu filho, confirmando os dados de que a aprendizagem das classes de habilidades tem também uma relação intergeracional (Del Prette \& Del Prette, 2013). Além disso, o fato de Isabel continuar a fazer os pedidos pela filha, faz com que tal habilidade continue sendo menos desenvolvida em sua filha, reforçando tal comportamento. Desta forma, percebe-se a importância das habilidades sociais das mães no seu manejo com seus filhos. Nesse sentido, a convergência entre as práticas positivas maternas e as habilidades sociais dos filhos foi evidenciada em um estudo brasileiro com 24 mães e seus filhos adolescentes (Sabbag \& Bolsoni-Silva, 2015). As autoras apontam que quando as mães valorizam o interesse dos adolescentes, esses participam de maneira ativa ao expressarem suas opiniões nas interações.

Apenas Isabel percebe uma evolução em suas habilidades sociais, a qual atribui à entrada no curso técnico e posteriormente na graduação. Compreende-se que as habilidades sociais podem aumentar com a escolaridade, devido aos contextos de interação proporcionados e às experiências positivas percebidas (Del Prette $\&$ Del Prette, 2014). Débora, por sua vez, não completou o Ensino Médio e refere o isolamento social. Com o afastamento entre usuários e não usuários torna-se ainda mais difícil desenvolver o repertório de habilidades sociais das participantes de modo que eles contribuam para o seu bem estar, melhorando assim, seus déficits ou trabalhando para que um novo repertório comportamental seja adquirido. Por exemplo, a habilidade de ter desenvoltura em um contexto social para que possam adquirir novas amizades fora do ambiente em que haja uso de drogas. Nesse sentido, a baixa escolaridade implica simultaneamente em maiores situações estressoras e ausência de recursos, conforme um estudo holandês realizado com 3050 participantes (Mulder, Bruin, Schreurs, Ameijden, \& Woerkum, 2011). Os autores sugerem o Treinamento em Habilidades Sociais como uma ferramenta estratégica para grande parte da população, especialmente aquela com baixa escolaridade.

Por fim, os três casos compartilham de dificuldades nas relações interpessoais durante o tratamento. Assim, quando os déficits em habilidades sociais persistem, o tratamento pode ser menos proveitoso, por não dispor de recursos naquela situação ou pelos trabalhos em intervenção acontecerem, muitas vezes, focando nos déficits dos participantes e não nos recursos. Desta forma, alguém que apresenta agressividade, pode ter ao mesmo tempo facilidade de se comunicar com desconhecidos, recurso esse que pode ser 
trabalhado ao ser identificado nos instrumentos disponíveis de habilidades sociais. Sendo assim, ressalta-se a necessidade de intervenções focais voltadas ao aumento das habilidades sociais de mulheres usuárias de crack, principalmente habilidades que dizem respeito ao autocontrole, recusa e estabelecimento de vínculos com pessoas fora do ambiente de uso de drogas (Andretta et al., 2016). Com isso, haverá contribuições para interações satisfatórias entre profissionais e pacientes, bem como entre os próprios pacientes, a fim de que se sintam mais dispostos a participarem de grupos terapêuticos, além de se sentirem à vontade para fazer pedidos e expressarem suas dúvidas em relação ao tratamento.

\section{Considerações Finais}

A compreensão dos casos revelou a importância das habilidades sociais no decorrer do ciclo vital e no contexto do uso de drogas. As participantes relataram dificuldades em suas habilidades sociais desde a infância, devido a suas características pessoais e carência de contextos que permitissem o desenvolvimento de um repertório socialmente habilidoso. Com isso, intervenções preventivas deveriam dar ênfase aos momentos críticos do desenvolvimento, a fim de evitar comportamentos de risco, como o uso de drogas.

Os três casos apresentaram dificuldades na utilização das habilidades sociais, que poderiam ser desenvolvidas a partir de intervenções como o Treinamento em Habilidades Sociais, melhorando as interações sociais inclusive no contexto do tratamento ao uso de drogas. Ao analisar as habilidades sociais pelo inventário e pela entrevista, foi possível uma compreensão mais profunda desse fenômeno. Assim, observa-se que a entrevista clínica permitiu analisar as habilidades sociais de mulheres usuárias de crack no decorrer do ciclo vital, identificado dificuldades e recursos das participantes. Salienta-se que as habilidades sociais em que cada participante manifestou maior facilidade, como a cordialidade, poderiam ser as primeiras habilidades a serem trabalhadas em uma intervenção, a fim de promover a motivação para a realização das demais atividades. Desta forma, indica-se a continuidade de estudos com a utilização desta entrevista, a fim de obter informações relevantes para a compreensão do caso e para o planejamento de intervenções.

Como limitações do estudo, foram utilizados instrumentos de autorrelato. Sugere-se que futuros estudos contemplem a observação do comportamento em diferentes contextos de interação, considerando as classes de respostas (assertiva, agressiva e passiva) na avaliação. Além disso, também se sugere que no planejamento do Treinamento em Habilidades Sociais as comorbidades psiquiátricas sejam consideradas, avaliando a intensidade dos sintomas no decorrer da intervenção.

\section{Referências}

American Psychiatric Association. (2002). Manual diagnóstico e estatístico dos transtornos mentais. DSM IV-TR (4. ed.). Porto Alegre, RS: Artes Médicas.

American Psychiatric Association. (2014). Manual diagnóstico e estatístico de transtornos mentais. DSM-5. Porto Alegre, RS: Artmed.

Amorim, P. (2000). Mini International Neuropsychiatric Interview (MINI): Validação de entrevista breve para diagnóstico de transtornos mentais. Revista Brasileira de Psiquiatria, 22(3), 106-115. doi:http://dx.doi.org/10.1590/ S1516-44462000000300003

Andretta, I., Limberger, J., \& Oliveira, M. S. (2014). Abandono de tratamento de adolescentes com uso abusivo de substâncias que cometeram ato infracional. Aletheia, 43(44), 116-128. Recuperado em http://www.redalyc.org/articulo. oa?id=115039411009

Andretta, I., Limberger, J., \& Schneider, J. A. (2016). Social skills in crack users: Differences between men and women. Psicologia Reflexão e Crítica, 29(45), 1-8. doi:10.1186/s41155-016-0054-4

Angélico, A. P., Crippa, J. A. S., \& Loureiro, S. R. (2006). Fobia social e habilidades sociais: Uma revisão da literatura. Interação em Psicologia, 10(1), 113-125. Recuperado em http://revistas. ufpr.br/psicologia/article/viewFile/5738/4175

Associação Brasileira de Empresas de Pesquisa. (2015). Critérios de Classificação Econômica 
Brasil. Recuperado em http://www.abep.org/ criterio-brasil

Botvin, G. J., \& Griffin, K. W. (2015). Treinamento de habilidades para a vida. In S. G. Murta, C. Leandro-Grança, \& K. B. Santos (Eds.), Prevenção e promoção em Saúde Mental: Fundamentos, planejamento e estratégias de intervenção (pp. 405-418). Novo Hamburgo, RS: Sinopys.

Caemmerer, J. M., \& Keith, T. Z. (2015). Longitudinal, reciprocal effects of social skills and achievement from kindergarten to eighth grade. Journal of School Psychology, 53, 265-281. doi:10.1016/j.jsp.2015.05.001

Cunha, J. A. (1993). Psicodiagnóstico-R (4. ed.). Porto Alegre, RS: Artes Médicas.

Del Prette, Z. A. P., \& Del Prette, A. (2001). Inventário de Habilidades Sociais: Manual de aplicação, apuração e interpretação. São Paulo, SP: Casa do Psicólogo.

Del Prette, Z. A. P., \& Del Prette, A. (2013). Social Skills Inventory (SSI-Del-Prette): Characteristics and studies in Brazil. In F. L. Osório (Ed.), Social anxiety disorders: From theory to practice (pp. 49-62). New York: Nova Science.

Del Prette, Z. A. P., \& Del Prette, A. (2014). Psicologia das relações interpessoais: Vivências para o trabalho em grupo. Petrópolis, RJ: Vozes.

Del Prette, Z. A. P., Ferreira, B. C., Dias, T. P., \& Del Prette, A. (2015). Habilidades sociais ao longo do desenvolvimento: Perspectivas de intervenção em saúde mental. In S. G. Murta, C. Leandro-Grança, \& K. B. Santos (Eds.), Prevenção e promoção em Saúde Mental: Fundamentos, planejamento e estratégias de intervenção (pp. 318-340). Novo Hamburgo, RS: Sinopys.

Feldens, A. C. M., Silva, J. G. D., \& Oliveira, M. D. S. (2011). Avaliação das funções executivas em alcoolistas. Cadernos de Saúde Coletiva, 19, 164-171. Recuperado em http://www.cadernos. iesc.ufrj.br/cadernos/images/csc/2011_2/artigos/csc_v19n2_164-171.pdf

Feitosa, F. B. (2013). Habilidades Sociais e sofrimento psicológico. Arquivos Brasileiros de Psicologia, 65(1), 38-50.

Fernandes, C. S., Falcone, E. M. O., \& Sardinha, A. (2012). Deficiências em habilidades sociais na depressão: Estudo comparativo. Psicologia: Teoria e Prática, 14(1). Recuperado em http://pepsic.bvsalud.org/scielo.php?script=sci
arttext\&pid=S1516-36872012000100014\&lng= pt\&tlng $=\mathrm{pt}$

First, M. B., Gibbon, M., Spitzer, R. L., \& Williams, J. B. W. (1997). Entrevista estruturada para transtornos de personalidade do DSM-IV, SCID-II (1,0): Versão brasileira (N. M. M. Melo \& B. P. Rangé, Trads.). Rio de Janeiro, RJ.

Jansson, L. (1984). Social skills training for unipolar depression: A case study. Scandinavian Journal of Behaviour Therapy, 13(4), 237-241. doi:10.1080/16506078409455717

Leme, V. B. R., Fernandes, L. M., Jovarini, N. V., \& Achkar, A. M. (2015). Relações interpessoais e habilidades sociais de adolescentes de contextos sociais vulneráveis. In Z. A. P. Del Prette, A. B. Soares, C. S. Pereira-Guizo, M. F. Wagner, \& V. B. R. Leme, Habilidades sociais: Diálogos e intercâmbios sobre pesquisa e prática (pp. 103127). Novo Hamburgo, RS: Sinopsys.

Limberger, J., \& Andretta, I. (2015). A compreensão das habilidades sociais a partir do ciclo vital. In Z. A. P. Del Prette, Anais do V Seminário Internacional de Habilidades Socias. Pirenópolis, GO, Brasil

Limberger, J., \& Andretta, I. (no prelo). Associações entre habilidades sociais e comorbidades psiquiátricas de mulheres usuárias de crack. Estudos e Pesquisas em Psicologia.

Limberger, J. (2016). Mulheres em tratamento pelo uso do crack: Habilidades socias e características clínicas (Dissertação de mestrado, Universidade do Vale do Rio dos Sinos, São Leopoldo, RS, Brasil). doi:10.13140/RG.2.1.1575.8326

Melo, N. M. M., \& Rangé, B. P. (Trads.). (2008). Entrevista estruturada para transtornos de personalidade do DSM-IV, SCID-II $(1,0)$ : Versão brasileira. Rio de Janeiro, RJ.

Mulder, B. C., Bruin, M., Schreurs, H., Ameijden, E. J. C., \& Woerkum, C. M. J. (2011). Stressors and resources mediate the association of socioeconomic position with health behaviours. BMC Public Health, 11(789), 1-10. doi:10.1186/14712458-11-798

Nascimento, E. (2004). Adaptação e padronização brasileira da Escala de Inteligência Wechsler para Adultos. Porto Alegre, RS: Casa do Psicólogo.

Nilsen, W., Karevold, E., Røysamb, E., Gustavson, K., \& Mathiesen, K. S. (2013). Social skills and 
depressive symptoms across adolescence: Social support as a mediator in girls versus boys. Journal of Adolescence, 36, 11-20. doi:10.1016/j. adolescence.2012.08.005

Sabbag, G. M., \& Bolsoni-Silva, A. T. (2015). Relações entre práticas educativas e as habilidades sociais educativas de mãe de adolescentes. In Z . A. P. Del Prette, A. B. Soares, C. S. Pereira-Guizo, M. F. Wagner, \& V. B. R. Leme, Habilidades sociais: Diálogos e intercâmbios sobre pesquisa e prática (pp. 103-127). Novo Hamburgo, RS: Sinopsys.

Schneider, J. A., Limberger, J., \& Andretta, I. (2016). Habilidades sociais e drogas: Revisão sistemática da produção científica nacional e internacional. Avances en Psicología Latinoamericana, 34(2), 339-350. doi:10.12804/apl34.2.2016.08

Segrin, C. (2010). Social skills deficits associated with depression. Clinical Psychology Review, 20(3), 379-403.

Sheehan, D. V., Lecrubier, Y., Sheehan, K. H., Amorim, P., Janavs, J., Weiller, E., ...Dunbar G. C. (1998). The Mini-International Neuropsychiatric Interview (M.I.N.I.): The development and validation of a structured diagnostic psychiatric interview for DSM-IV and ICD-10. Journal Clinic Psychiatry, 59(Suppl. 20), 22-33.

Sintra, C. I. F., Lopes, P., \& Formiga, N. (2011). Condutas antissociais e delitivas e habilidades sociais em contexto forense. Psicologia Argumento, 29, 383-399.

Terroso, L. B., Pedroso, F. N., \& Kurle, A. M. (2015). Habilidades sociais na adolescência: Conceituação, avaliação e intervenção. In I. I. L. Argimon, C. S. Esteves, \& G. W. Wendt (Eds.), Ciclo vital: Perspectivas contemporâneas em avaliação e intervenção. Porto Alegre, RS: Editora Universitária da Pontifícia Universidade Católica do Rio Grande do Sul.
Tong, A., Sainsbury, P., \& Craig, J. (2007). Consolidated criteria for reporting qualitative research (COREQ): A 32-item checklist for interviews and focus groups. International Journal for Quality in Health Care, 19(6), 349-357. doi:10.1093/intqhe/mzm042

Vorobjov, S., Saat, H., \& Kull, M. (2014). Social skills and their relationship to drug use among 15-16-year-old students in Estonia: An analysis based on the ESPAD data. Nordic Studies on Alcohol and Drugs, 31. Recuperado em http:// www.degruyter.com/view/j/nsad

Wagner, M. F., \& Oliveira, M. S. (2015). Habilidades sociais no abuso e na dependência de maconha. In Z. A. P. Del Prette, A. B. Soares, C. S. Pereira-Guizo, M. F. Wagner, \& V. B. R. Leme, Habilidades sociais: Diálogos e intercâmbios sobre pesquisa e prática. Novo Hamburgo, RS: Sinopys.

Wechsler, D. (1997). Weschsler Adult Intelligence Scale-III. San Antonio, TX: The Psychological Corporation.

Yin, R. K. (2010). Estudo de caso: Planejamento e métodos. Porto Alegre, RS: Bookman.

Recebido: 22/02/2016

$1^{a}$ revisão: $15 / 08 / 2016$ Aceite final: $1 \% 09 / 2016$ 